\title{
Acute exposure of adult male rats to dietary phytoestrogens reduces fecundity and alters epididymal steroid hormone receptor expression
}

\author{
A Glover and S J Assinder \\ Department of Anatomy and Structural Biology, School of Medical Sciences, University of Otago, PO Box 913, Dunedin, New Zealand \\ (Requests for offprints should be addressed to S J Assinder; Email: stephen.assinder@stonebow.otago.ac.nz)
}

\begin{abstract}
Phytoestrogens are plant-derived compounds with oestrogenic activity. They are common in both human and animal diets, particularly through soy-based foods. This study assessed whether exposure of adult male rats to a high phytoestrogen diet for 3-25 days affected their fertility, and assessed possible mechanisms through which phytoestrogens may disrupt fertility. Adult males, fed a high phytoestrogen diet for 3 days, demonstrated significantly reduced fecundity. This effect was transient, with fecundity returning to control levels by day 12 . The expression of oestrogen receptor- $\alpha$ and androgen receptor
\end{abstract}

mRNA was increased in the initial segment of the epididymis, but decreased in the cauda epididymis following 3 days on the high phytoestrogen diet. Epididymal sperm counts cannot account for the reduction in fertility at day 3. However, lipid peroxidation of epididymal sperm was significantly increased in animals fed a high phytoestrogen diet for 3 days. Disruption of the steroid regulation of the epididymis by phytoestrogens may alter its function, resulting in decreased quality of sperm, and thereby reducing fecundity.

Journal of Endocrinology (2006) 189, 565-573

\section{Introduction}

Phytoestrogens are plant-derived, non-steroidal compounds, able to activate oestrogen receptor- $\alpha(\operatorname{ER} \alpha)$ and ER $\beta$ (Kuiper et al. 1997, 1998). Phytoestrogens can be divided into three main classes - isoflavones, coumestans and lignans. Soy beans and foods derived from them are rich sources of isoflavones, such as genistein.

Oestrogen is vital for the development, maintenance and function of the male reproductive system. Administration or deprivation of oestrogen, both during development and in the adult, has been shown to cause structural and functional changes in the male reproductive tract, including infertility. Neonatal treatment of male rats with oestrogenic chemicals reduces testicular and epididymal sperm concentration, plasma testosterone (Goyal et al. 2003, Sharpe et al. 2003), Sertoli cell number (Atanassova et al. 2005), alters testicular gene expression (Adachi et al. 2004) and causes rete tubule distension and reduced epithelial height in the efferent ducts (Aceitero et al. 1998, Fisher et al. 1998, 1999). The absence of a functional ER $\alpha$ also causes distension of the rete testes, efferent ducts and epididymides, and causes infertility (Lubahn et al. 1993, Eddy et al. 1996, Hess et al. 2000). In adult rats, very similar structural and functional abnormalities to those seen in
ER $\alpha$ knockout mice can be induced by the antioestrogen ICI 182,780 (Oliveira et al. 2001), whilst the administration of the synthetic oestrogen diethylstilboestrol (DES) to adult rats reduces reproductive organ weights, epididymal sperm numbers and fertility (Goyal et al. 2001).

Phytoestrogen exposure during the neonatal period causes reproductive abnormalities similar to those induced by other oestrogenic chemicals, including the downregulation of testicular gene expression (Adachi et al. 2004). The effect of exposure to phytoestrogens in the adult has received very little attention.

The epididymis, a steroid-dependent organ, is responsible for the post-testicular maturation and storage of sperm. Because of the composition of the sperm plasma membrane and their lack of cytoplasm, sperm in the epididymis are susceptible to damage from reactive oxygen species (Aitken \& Vernet 1998). The epididymis protects sperm from oxidative damage by secretion of antioxidant enzymes (Zini \& Schlegel 1997) under steroid regulation (Schwaab et al. 1998).

The following experiments tested our hypotheses that exposure to high levels of dietary phytoestrogens will reduce fertility, and that this is due to altered steroid regulation of the reproductive tract, increasing oxidative stress of sperm. 


\section{Materials and Methods}

\section{Diets}

Two diets were used in this study: a low phytoestrogen diet (control) and a high phytoestrogen diet (treatment). The low phytoestrogen diet was Diet 86 (Sharpe, Palmerston North, New Zealand) containing (w/w) $78 \cdot 8 \%$ cereal, $1 \cdot 5 \%$ skimmed milk, $7 \%$ fish meal, $6 \%$ bone meal, $0 \cdot 5 \% \mathrm{NaCl}, 0 \cdot 1 \%$ rodent premix and $1 \%$ soy meal. The total phytoestrogen content of the low phytoestrogen diet was $112 \mu \mathrm{g} / \mathrm{g}$ comprised of $53.5 \mu \mathrm{g} / \mathrm{g}$ genistein, $32.5 \mu \mathrm{g} / \mathrm{g}$ daidzin and $26 \mu \mathrm{g} / \mathrm{g}$ glycitein. The high phytoestrogen diet was Diet RMH 3500 (Reliance Stockfoods, Dunedin, New Zealand) and contained (w/w) 61\% cereal, $3 \cdot 5 \%$ skimmed milk, $2 \cdot 5 \%$ fish meal, $7 \cdot 5 \%$ meat/bone meal, $0 \cdot 4 \% \mathrm{NaCl}, 0 \cdot 3 \%$ rodent premix and $25 \%$ soy meal. The total phytoestrogen content of the high phytoestrogen diet was $465 \mu \mathrm{g} / \mathrm{g}$ made up of $225 \mu \mathrm{g} / \mathrm{g}$ genistein, $180 \mu \mathrm{g} / \mathrm{g}$ daidzin and $60 \mu \mathrm{g} / \mathrm{g}$ glycitein. Concentrations of isoflavones are the sum of individual isomers, as determined by an independent analysis by the Department of Food Science and Human Nutrition, Iowa State University, Iowa, IO, USA.

\section{Animals}

This study was approved by the University of Otago Animal Ethics Committee. To exclude developmental effects of phytoestrogen exposure, all male and female Wistar rats used in the experiments were bred from females fed the low phytoestrogen diet prior to mating and during pregnancy and lactation. The offspring were weaned onto the low phytoestrogen diet and maintained on this diet until adulthood (90 days of age) when they were included in the study. The rats were group housed with others of the same sex and kept under a $12 \mathrm{~h}$ light:12 $\mathrm{h}$ darkness cycle and had food and water available ad libitum. At the conclusion of experiments, rats were killed by $\mathrm{CO}_{2}$ inhalation.

\section{Experiment 1: Effects of a high phytoestrogen diet on fertility}

All rats (male and female) were mated to provide a baseline litter size for each female. Females fed a low phytoestrogen diet were housed for 4 days and nights with a male, also fed a low phytoestrogen diet, to allow mating to occur. The subsequent litter size for each female was recorded. Any female or male that failed to produce a litter was excluded from the study.

Following the birth of the first litters, females $(n=48)$ were continually fed the low phytoestrogen diet whilst males were randomly assigned to a control $(n=6)$ or treatment group $(n=6)$. The control group was continued on the low phytoestrogen diet. The treatment group was transferred to the high phytoestrogen diet (day 0).
All males were then mated 3, 6, 12 and 25 days after the initiation of dietary regimes, overnight with a prooestrous female (as determined by vaginal smear histology) in individual cages with the low phytoestrogen diet provided. Males were removed and the presence of sperm in vaginal smears confirmed that mating had occurred. Females were housed individually until parturition and the number and sex of the pups were determined. The number of pups in the first (baseline) litter of each female was compared with the number in the second litter after mating with either a male continually fed the low phytoestrogen diet, or a male which had been transferred to the high phytoestrogen diet. After the final mating (day 25) the males were killed.

\section{Experiment 2: Effects of a high phytoestrogen diet on fertility parameters}

A second study assessed the effect of increasing periods of dietary phytoestrogen exposure on epididymal sperm counts, epididymal steroid hormone receptor expression and testicular testosterone and plasma gonadotrophin levels. Adult male rats were randomly allocated to either the control group or the treatment group. The treatment group was transferred to the high phytoestrogen diet (day $0)$ while the control group remained on the low phytoestrogen diet. After 3, 6, 12 and 25 days rats $(n=8$ each time-point) from both the control and treatment groups were killed and tissues collected. One epididymis from each rat was immediately frozen in liquid nitrogen and subsequently stored at $-80{ }^{\circ} \mathrm{C}$. The other was immersed in Bouin's fixative for $24 \mathrm{~h}$ and then stored in $70 \%$ ethanol at room temperature until dehydrated and embedded in paraffin wax prior to histological examination. Trunk blood was collected in heparinised tubes and centrifuged to separate plasma from the haematocrit. The plasma was removed and stored at $-30{ }^{\circ} \mathrm{C}$.

\section{Experiment 3: Effects of a high phytoestrogen diet on oxidative stress}

To determine if reduced litter size is associated with oxidative damage, a third study was carried out to assess the effects of phytoestrogens on oxidative stress of epididymal sperm after 3 days of exposure to a high phytoestrogen diet. Adult male rats were raised on the low phytoestrogen diet and randomly assigned to either the control $(n=10)$ or treatment $(n=10)$ groups. The treatment group was transferred to the high phytoestrogen diet. After 3 days the rats were killed by $\mathrm{CO}_{2}$ inhalation and epididymides were removed and stored on ice for the lipid peroxidation experiment.

\section{Sperm counts and morphology}

Counts of epididymal sperm were performed on the four regions of one epididymis per rat. Each segment was 
thawed on ice and minced in $1 \mathrm{ml} 0.9 \%(\mathrm{w} / \mathrm{v})$ saline for $90 \mathrm{~s}$ using two razor blades according to the method of Taylor et al. (1985). The average count for four separate aliquots was calculated. The mean coefficient of variation was $11.53 \%$.

The diluted homogenates used for sperm counts were also used to assess sperm morphology. The sperm suspension was further diluted to allow individual sperm to be clearly assessed. Ten microlitres of the sperm suspension were placed on a glass slide and covered with a glass coverslip. The slide was left to sit at room temperature for 1 min to allow the saline and sperm to settle.

Under the $\times 40$ objective lens a minimum of 200 sperm was classified as being of normal morphology, or as having a head defect or a tail defect. Head defects included a sideways, misshapen or double head. Examples of tail defects are the tail being significantly curled or bent up towards the head and sperm having a double tail. The percentage of normal and abnormal sperm was determined for each animal.

\section{Plasma gonadotrophin levels}

RIAs were performed to measure the plasma concentration of luteinizing hormone (LH) and folliclestimulating hormone (FSH), as previously described (Nicholson et al. 1991). The limits of detection for the LH and FSH assays were $0.12 \mathrm{ng} / \mathrm{ml}$ and $0.5 \mathrm{ng} / \mathrm{ml}$ respectively. The mean intra-assay coefficient of variation for the two LH assays was $14 \cdot 06 \%$, while the interassay coefficient of variation was $18 \cdot 07 \%$. For the FSH assays, the mean intra-assay coefficient of variation was $17 \cdot 54 \%$, and the variation between assays was $30 \cdot 29 \%$.

\section{Testicular testosterone levels}

Testosterone was extracted from testes of rats from experiment 2 and experiment 3 at 3 days from a known amount of tissue by homogenisation with $70 \%$ methanol in glass tubes. The tubes were left at $4{ }^{\circ} \mathrm{C}$ overnight and then centrifuged at $3000 \mathrm{~g}$ for $30 \mathrm{~min}$ at $4{ }^{\circ} \mathrm{C}$. The supernatant was transferred to a fresh glass tube, dried and extract resuspended in $1 \mathrm{ml}$ testosterone buffer $(0.158 \mathrm{~mol} / 1$ $\mathrm{Na}_{2} \mathrm{HPO}_{4}, \quad 0.044 \mathrm{~mol} / 1 \quad \mathrm{NaH}_{2} \mathrm{PO}_{4} \cdot \mathrm{H}_{2} \mathrm{O}, \quad 0.154 \mathrm{~mol} / 1$ $\mathrm{NaCl}, 0.015 \mathrm{~mol} / 1 \mathrm{NaN}_{3}$ and $0 \cdot 1 \%$ (w/v) gelatine; $\mathrm{pH}$ $7 \cdot 0-7 \cdot 2)$ overnight at $4{ }^{\circ} \mathrm{C}$. Testosterone was measured by RIA as previously described (Yeung et al. 1988). The antiserum used was 85/6 (Department of Anatomy, University of Bristol, Bristol, UK). The limit of detection of the assay was $40 \mathrm{pg} / \mathrm{ml}$ and the interassay coefficient of variation was $10 \cdot 8 \%$.

\section{Steroid hormone receptor expression}

Epididymides were divided into the four morphologically distinct regions - the initial segment, caput, corpus and cauda - according to Serre \& Robaire (1998). ER $\alpha, E R \beta$ and androgen receptor (AR) expression was measured in the four epididymal regions of $3-$ and 6-day rats. Tissue was crushed under liquid nitrogen and total RNA extracted from each region using TriZol (Invitrogen Life Technologies, Inc) following the manufacturer's protocol. The RNA pellet was resuspended in RNase/DNase free water and the concentration and purity of the sample was measured. Total RNA $(1 \mu \mathrm{g})$ was reverse transcribed with random hexamers into cDNA in a $20 \mu \mathrm{l}$ reaction according to the manufacturer's protocol (MultiScribe II reverse transcription kit; Applied Biosystems, Branchburg, NJ, USA).

Steroid receptor expression was quantitated by real-time PCR of cDNA using the Sequence Detection System 7000 (Applied Biosystems). Primer sets and fluorescent TaqMan MGB probes were designed, using the Applied Biosystems Primer Express program, to detect rat ER $\alpha$ (X61098), ER $\beta$ (NM_012754) and AR (NM_012502). Forward primer, reverse primer and probe sequences for ER $\alpha$ were $5^{\prime}$-CCACCGAGT CCTGGACAAGA-3', 5'-CGGATATGGGAAAGGA TGA- $3^{\prime}$ and $5^{\prime}$-CACAGACACTTTGATCCACTTG ATGGCC-3' respectively. For ER $\beta$, forward primer, reverse primer and probe were $5^{\prime}$-CACTGCACTT

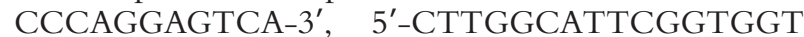

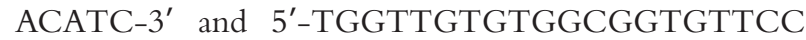
TCATA $-3^{\prime}$ respectively. The ER $\beta$ primers and probe recognise both isoforms of ER $\beta$-ER $\beta 1$ (NM_012754) (Kuiper et al. 1996) and ERß2 (AB190770) (Chu \& Fuller 1997). AR forward and reverse primer sequences were $5^{\prime}$-GGGACATGCGTTTGGACAGT-3' and 5'-CCACAGATCAGGCAGGTCTTC-3', with probe sequence $5^{\prime}$-CCAGGGACCACGTTTTACCCATCG ACTA-3'. Absolute standards $\left(2 \times 10^{-4}\right.$ to $4 \times 10^{-10}$ ng) prepared from purified cDNA identical to the real-time PCR products of the targets $(\mathrm{ER} \alpha, \mathrm{ER} \beta$ and $A R$ ) were included on each plate, to ensure equal efficiency of amplification between standards and sample products. No template controls and no reverse transcriptase controls were used as negative controls. The reaction mixture contained $12.5 \mu \mathrm{l}$ TaqMan Universal PCR Master Mix (Applied Biosystems), $0.9 \mu \mathrm{mol} / 1$ of the forward and reverse primers, $0.25 \mu \mathrm{mol} / \mathrm{l}$ of the $5^{\prime}$ FAM labelled TaqMan MGB probe and $50 \mathrm{ng}$ sample cDNA, in a final reaction volume of $25 \mu \mathrm{l}$. The standards, samples and negative controls for each target were run in triplicate with a thermal cycling profile of $50{ }^{\circ} \mathrm{C}$ for $2 \mathrm{~min}, 95^{\circ} \mathrm{C}$ for $10 \mathrm{~min}$ and 40 cycles of $95^{\circ} \mathrm{C}$ for $15 \mathrm{~s}$ and $60^{\circ} \mathrm{C}$ for $1 \mathrm{~min}$. The concentration of target cDNA in each sample was calculated using the linear equation of the appropriate standard curve and normalised to the amount of total RNA used in the reverse transcription reaction. 
Tubule and lumen diameters in proximal epididymis

Fixed proximal epididymides were dehydrated, wax embedded, cut into $4 \mu \mathrm{m}$ sections and stained with haematoxylin and eosin. Sections were viewed on a light microscope under the $\times 4$ objective lens and photos were taken of the sections using a Spot digital camera and software (Diagnostic Instruments, Sterling Heights, MI, USA). A modified version of Cruz-Orive's (1987) selector method was used to select profiles of the epididymis. A grid of parallel, point-sampled, intercept lines (the points being $4 \mathrm{~cm}$ apart on lines that are $2 \mathrm{~cm}$ apart) was orientated by randomly selected angles over the displayed images using a sine-weighted angle reference frame. The lumen and tubule diameters of tubules selected by the intercept lines were measured along the parallel lines using the measure tool in the Spot program.

\section{Sperm lipid peroxidation}

Each epididymis was placed in $2.5 \mathrm{ml} 0.9 \%$ saline and cut lengthwise with a razor blade to release sperm. Sperm counts were made for each sample as described above. The thiobarbituric acid reactive substances assay, measuring malondialdehyde (MDA), a by-product of lipid peroxidation, was based on the method of Ohkawa et al. (1979). MDA standards were made by acid hydrolysis of tetraethoxypropane and serially diluted $(0-0 \cdot 25 \mu \mathrm{mol} / \mathrm{l})$. The thiobarbituric acid (TBA) reaction mix was comprised of $3 \mathrm{ml} \mathrm{H}_{2} \mathrm{O}, 3 \mathrm{ml} 70 \%$ perchloric acid (BDH Chemicals Ltd, Poole, Dorset, UK) and 0.03 g TBA. Two hundred microlitres of TBA reaction mix were added to $800 \mu \mathrm{l}$ sperm suspension or $800 \mu \mathrm{l}$ MDA standard in $15 \mathrm{ml}$ plastic screw top tubes. The tubes were incubated in a boiling waterbath for $15 \mathrm{~min}$ and cooled on ice for $3 \mathrm{~min}$. The coloured adduct was extracted by vortexing with

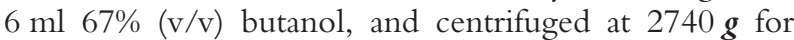
5 min at $4{ }^{\circ} \mathrm{C}$. Two hundred microlitres of the butanol phase were measured fluorometrically with an excitation wavelength of $510 \mathrm{~nm}$ and an emission wavelength of $544 \mathrm{~nm}$. The concentration of MDA in the epididymal sperm samples was calculated using the linear equation from the standard curve and normalised to $2 \times 10^{7}$ sperm.

\section{Statistics}

All data given are means \pm S.E.M. Paired $t$-tests were used to compare litter sizes between the first and second litters of females. Differences in litter incidence was tested by Fisher's exact test. Sex ratios, body and epididymal weights, sperm counts, plasma gonadotrophin levels, realtime PCR, tubule measurements and lipid peroxidation results were compared by ANOVA. $P<0 \cdot 05$ was deemed statistically significant. Statistical analysis was carried out using GraphPad Prism 4·0 Software (GraphPad Software Inc,
San Diego, CA, USA). Datum points determined as outliers by Dixon's test were excluded from analyses (Sokal \& Rohlf 1981).

\section{Results}

\section{Litter sizes and sex ratios}

Five female rats were excluded from the study because they did not become pregnant or had only one pup following the initial mating. After they had been killed it was discovered that a control male had significantly smaller than average reproductive organs and below average testicular and epididymal sperm counts. Data from this male, including that of litter size, were excluded from analyses.

Five females did not become pregnant following the second mating. Three were housed with high phytoestrogen males and two were housed with low phytoestrogen males. The two females in the low phytoestrogen group had ambiguous vaginal smears prior to mating and subsequently failed to mate as determined by the absence of sperm. Therefore they were most likely not in prooestrus and were unreceptive. Of the three females in the high phytoestrogen group, one mated with a 12-day male had an ambiguous smear prior to mating, but did mate. This mating did not result in a litter. One female, housed with a 25-day treatment male, whilst pro-oestrus, as determined by vaginal cytology, failed to mate. The third female did mate, did not have an ambiguous smear but failed to produce a litter. This female was mated with a male after 6 days of treatment. Whilst all failures to produce litters following a successful mating occurred in pairings with males fed the high phytoestrogen diet, litter incidence was not significantly different.

There was no significant difference between the number of pups in the first and second litters at any of the four time-points when the females were mated only with males on a low phytoestrogen diet (Fig. 1A). However, litter sizes were significantly reduced $(P=0.017)$ for females mated with a male fed a high phytoestrogen diet for 3 days prior to mating (Fig. 1B). There was no significant change in litter size after the male was fed a high phytoestrogen diet for 6, 12 or 25 days (Fig. 1B). There was no difference in the incidence of litters, irrespective of litter size, between treatments or time-points and hence no difference in outright fertility.

The average ratios of male to female pups in the second litters ranged from 0.570 to 1.693 , and were not significantly different between the control and treatment groups.

\section{Body and epididymal weights}

The average total body weight for the day-3 control $(n=8)$ and treatment groups $(n=7)$ were $368 \pm 8 \mathrm{~g}$ and 

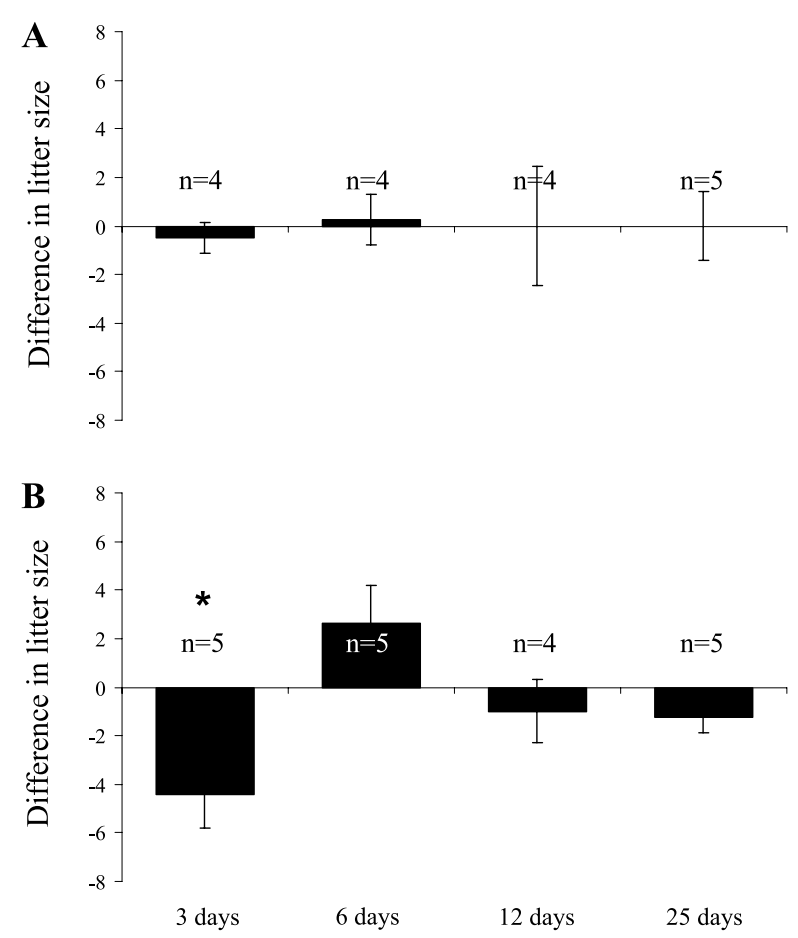

Time since change in diet

Figure 1 Mean \pm S.E.M. differences between the first and second litters when males were fed (A) a low or (B) a high phytoestrogen diet for $3,6,12$ and 25 days. The number of replicates for each determination ( $\mathrm{n}$ ) are given on or above the bars. ${ }^{*} P=0 \cdot 017$

$378 \pm 8$ g respectively. The average epididymal weight for the control group was $440 \pm 11 \mathrm{mg}$ while that for the high phytoestrogen treatment group was $471 \pm 10 \mathrm{mg}$. There were no significant differences in body or epididymal weights.

\section{Sperm counts and morphology}

Total epididymal sperm concentration in 3-day control $(n=8)$ and treatment groups $(n=7)$ were $1.94 \times$ $10^{-9} \pm 1.22 \times 10^{8} / \mathrm{g}$ and $1.93 \times 10^{9} \pm 1.02 \times 10^{-8} / \mathrm{g}$ respectively. These were not significantly different. Sperm morphology (Table 1) did not significantly differ between the treatment group and the control group at day 3 .

Table 1 Average percentage ( \pm S.E.M.) of epididymal sperm with normal morphology of day- 3 control $(n=8)$ and treatment rats $(n=6)$

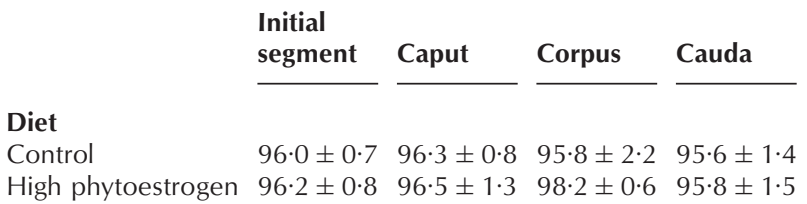

www.endocrinology-journals.org
Table 2 Mean plasma $\mathrm{LH}$ and $\mathrm{FSH}(\mathrm{ng} / \mathrm{ml} \pm$ S.E.M. $(n))$ and testicular testosterone $(\mathrm{ng} / \mathrm{ml}$ per $\mathrm{g} \pm$ S.E.M. $(n))$ in day-3 control and treatment groups

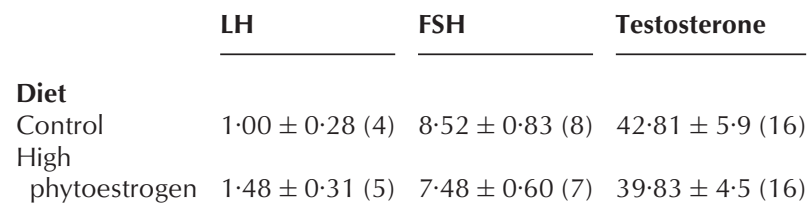

Plasma gonadotrophins and testicular testosterone

No statistically significant differences were found in the plasma concentrations of either LH or FSH or in testicular testosterone between the low phytoestrogen-fed control group and the high phytoestrogen-fed group at any time-point (Table 2).

\section{Steroid hormone receptor expression}

$\mathrm{ER} \alpha, \mathrm{ER} \beta$ and AR mRNA were all detected in each of the epididymal regions. However, the levels of expression differed between regions. Statistically significant differences were detected in the expression of ER $\alpha$ and AR mRNA between the low phytoestrogen and high phytoestrogen groups. In rats fed the high phytoestrogen diet for 3 days before they were killed, ER $\alpha$ expression in the initial segment was significantly increased compared with that in rats maintained on the control low phytoestrogen diet $(P=0.0007)$ while, in the cauda, ER $\alpha$ mRNA was significantly reduced $(P=0 \cdot 0003)$ (Fig. $2 \mathrm{~A})$. No differences were detected in ER $\beta$ expression in any of the epididymal regions after 3 days on the high phytoestrogen diet (Fig. 2A). After 3 days on the high phytoestrogen diet, AR expression was increased in the initial segment $(P=0 \cdot 0199)$ and decreased in the cauda $(P=0 \cdot 015)$ (Fig. $2 A)$. No statistically significant differences were detected in the expression of ER $\alpha$ or AR in the caput and corpus regions following 3 days on the high phytoestrogen diet. In the rats fed the high phytoestrogen diet for the 6 days before they were killed, no statistically significant differences were detected in the expression of $E R \alpha$ or AR in the initial segment or caput regions between the control and treatment groups (Fig. 2B). However, ER $\alpha$ expression was decreased in the corpus whilst $\operatorname{ER} \beta$ expression was significantly lower in the initial segment and corpora epididymis.

\section{Tubule and lumen diameters in proximal epididymis}

The sections were confirmed as being from the proximal epididymis by the presence of tall pseudostratified or tall columnar epithelium. There were no significant differences 

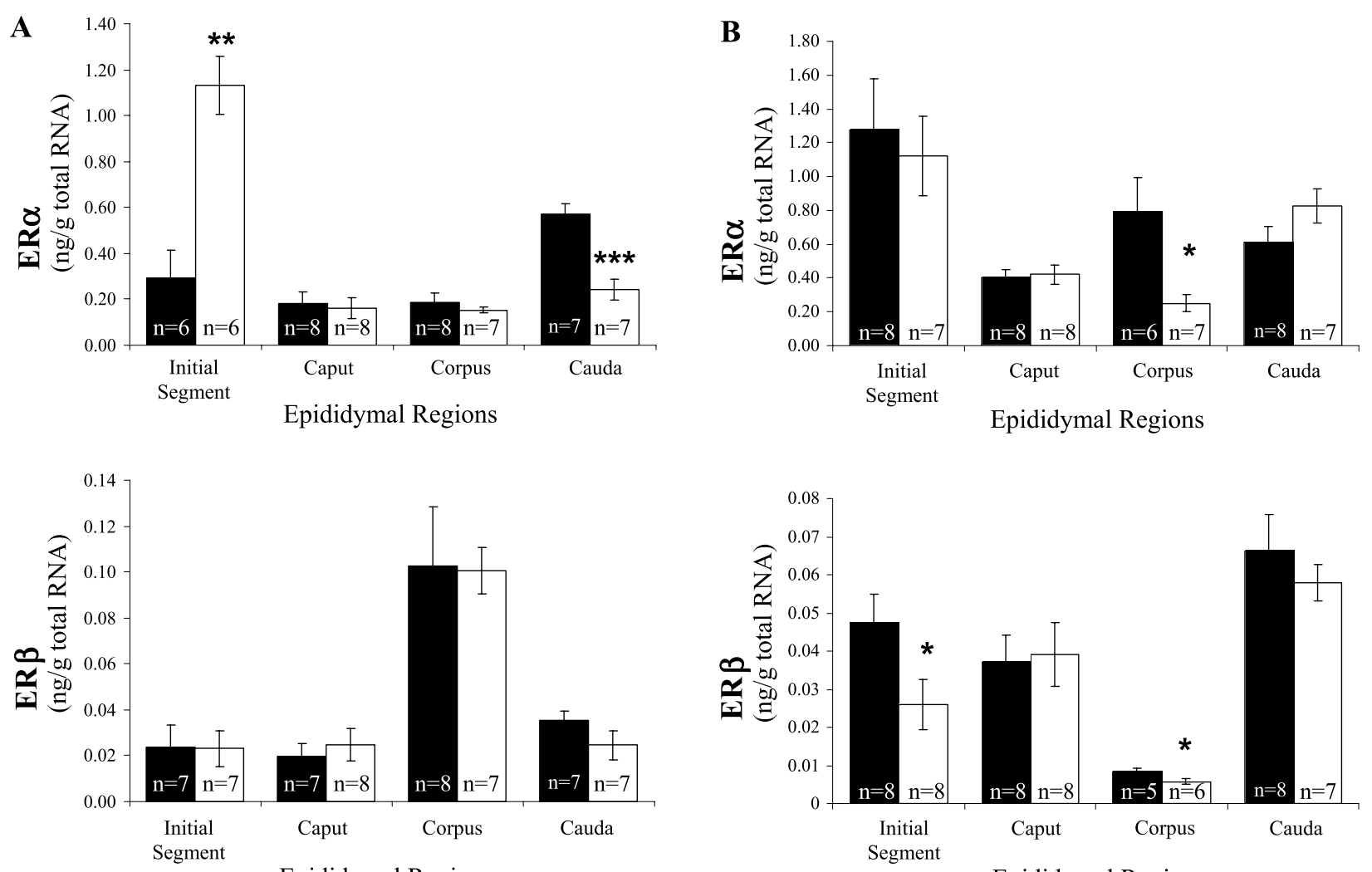

Epididymal Regions

Epididymal Regions
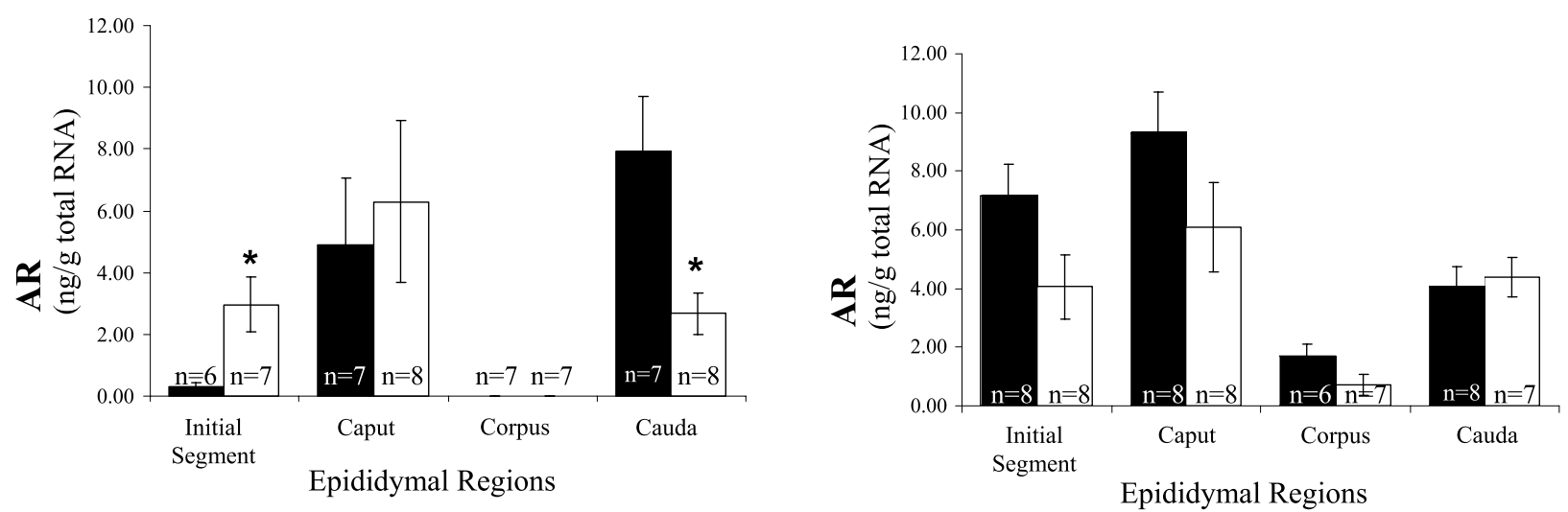

Figure 2 Mean \pm S.E.M. ER $\alpha, E R \beta$ and AR CDNA in the four regions of the epididymis for rats fed the low phytoestrogen diet (control, or rats fed a high phytoestrogen diet (treatment, $\square$ ) for (A) 3 days or (B) 6 days. The number of replicates for each determination (n) are given on the bars. ${ }^{*} P<0 \cdot 05 ;{ }^{*} P<0 \cdot 001 ;{ }^{* *} P<0 \cdot 0005$.

in lumen diameter, tubule diameter or tubule:diameter ratio between the day-3 control and treatment groups. The average measurements are shown in Table 3.

\section{Lipid peroxidation}

The concentration of MDA, as a marker for lipid peroxidation, was significantly higher $(P=0.041)$ in the sperm samples from rats fed a high phytoestrogen diet for 3 days compared with the samples from rats maintained on the low phytoestrogen diet (Fig. 3).

\section{Discussion}

This study assessed the reproductive effects of exposing adult male rats to high dietary phytoestrogens for 3-25 days. The diets used in this study were chosen to be 
Table 3 Average tubule and lumen diameters ( $\mu \mathrm{m} \pm$ S.E.M.) and ratios between the tubule and lumen diameters in the proximal epididymis for day-3 control $(n=7)$ and high phytoestrogen-fed rats $(n=6)$

\begin{tabular}{|c|c|c|c|}
\hline & $\begin{array}{l}\text { Tubule } \\
\text { diameter }\end{array}$ & $\begin{array}{l}\text { Lumen } \\
\text { diameter }\end{array}$ & Tubule:Iumen \\
\hline \multicolumn{4}{|l|}{ Diet } \\
\hline Control & $250 \pm 12$ & $163 \pm 10$ & $1.68 \pm 0.08$ \\
\hline High & & & \\
\hline phytoestrogen & $228 \pm 7$ & $140 \pm 6$ & $1.78 \pm 0.03$ \\
\hline
\end{tabular}

comparable with those used in previous studies (Weber et al. 2001, Wang et al. 2002) where the low and high diets generated plasma levels of phytoestrogens similar to those of western and Japanese men (Adlercruetz et al. 1993). In the study of Wang et al. (2002), rats that had a total daily phytoestrogen intake of $1.8 \mathrm{mg} / \mathrm{kg}$ and $19.25 \mathrm{mg} / \mathrm{kg}$ body weight, comparable with our study where intake was estimated at $3 \mathrm{mg} / \mathrm{kg}$ body weight (low diet) and $14 \mathrm{mg} / \mathrm{kg}$ (high diet), generated total phytoestrogen plasma concentrations of 60 and $861 \mathrm{mmol} / 1$ respectively. These levels were much lower than those generated in men by dietary supplements available over the counter (Rannikko et al. 2006). Exposure to a high phytoestrogen diet for 3 days reduced fecundity. This is a transient effect as rats exposed to the high phytoestrogen diet for a longer period of time did not show a reduction. The absence of changes following 6 or more days on the high phytoestrogen diet was consistent with previous long-term phytoestrogen exposure studies in men and adult rats. Men taking an isoflavone dietary supplement daily for 2 months showed no changes in blood hormone levels, testicular volume or semen parameters (Mitchell et al. 2001). Similarly, adult rats fed phytoestrogen-containing diets for 5 weeks or 12 months showed no differences in reproductive organ weights and testicular sperm numbers

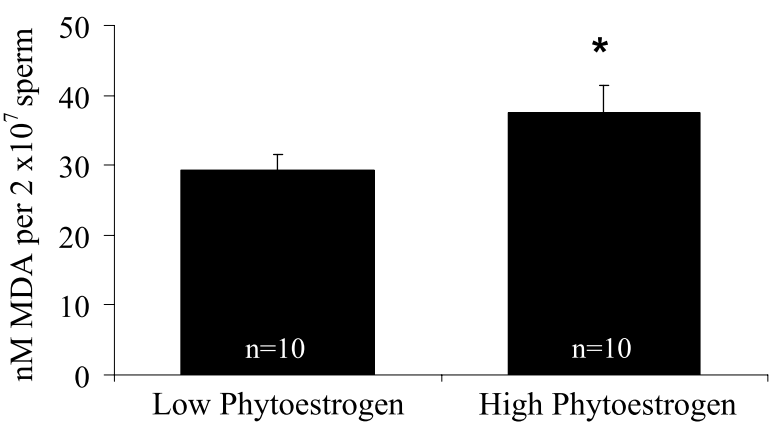

\section{Rodent Diets}

Figure 3 Mean \pm S.E.M. concentration of MDA, a marker of lipid peroxidation, in epididymal sperm from rats fed a low phytoestrogen diet or a high phytoestrogen diet for 3 days. The number of replicates for each determination $(n)$ are given on the bars. ${ }^{*} P=0 \cdot 041$. when compared with low or no phytoestrogen controls (Ashby et al. 2003, Faqi et al. 2004).

The reduction in litter size cannot be attributed to a depression of sexual behaviour following exposure to the high phytoestrogen diet. There was no difference in the failure to mate, as determined by sperm in vaginal smears, between the control and treatment groups. Goyal et al. (2001) induced infertility in adult male rats via the administration of low levels of DES for 12 days and attributed this result to depressed sexual behaviour or problems with epididymal sperm. The results of this study suggest that the latter is most likely. DES has a much greater oestrogenic potency than phytoestrogens (Kuiper et al. 1997) which would explain the more profound effect on fertility seen in that study compared with the present study.

No differences in plasma LH, FSH or testicular testosterone were determined between groups at any timepoint, indicating that the hypothalamo-pituitary-gonadal axis was not affected.

Furthermore, total epididymal sperm counts and the percentage of sperm with normal morphology were not altered after 3 days of exposure and therefore do not account for the reduction in fecundity.

It is most likely that the reduced fecundity seen in the 3-day treatment group was a result of altered epididymal function caused by disruption of steroid receptor expression. This was supported by the fact that after 6 days on the high phytoestrogen diet, fecundity was no longer reduced and there were no differences in expression of steroid receptors. After 3 days on a high phytoestrogen diet, both ER $\alpha$ and AR expression were decreased in the cauda epididymis. These changes were similar to those induced by the phytoestrogen genistein in the adult rat prostate (Fritz et al. 2002). In contrast, expression of both $\mathrm{ER} \alpha$ and $\mathrm{AR}$ are up-regulated in the initial segment after 3 days of a high phytoestrogen diet. This suggests that there is differential regulation of these steroid receptors in the epidydmis. ER $\beta$ expression remained unchanged throughout the epididymis, in contrast to the prostate where it was down-regulated (Fritz et al. 2002). These findings further highlight the differential regulation of the two oestrogen receptors previously described in the male reproductive tract (Oliveira et al. 2004). The present study demonstrates, for the first time, differential regulation of the ERs in the adult epididymis. It should also be noted that it describes, for the first time, fully quantitative regional differences in gene expression of $\mathrm{AR}, \mathrm{ER} \alpha$, and ER $\beta$ in the adult rat epididymis. Regional differences in gene expressions are well documented in the rat epididymis (Jervis \& Robaire 2001) and reflect the complex changing environment that sperm experience in the epididymis in order to mature and gain their fertilising ability. The regional expression patterns of $\mathrm{AR}$ in the caput, corpus and cauda epididymis are similar to relative levels determined by cDNA array analysis (Jervis \& Robaire 2001). Conflicting reports make the distribution 
of ER $\alpha$ and ER $\beta$ less clear. Fisher et al. (1997), Atanassova et al. (2001) and Yamashita (2004) did not detect ER $\alpha$ in any region of the adult rat epididymis by immunohistochemistry, while Sar \& Welsch (2000) detected ER $\alpha$ in the initial segment only. In contrast, Hess et al. (1997b) demonstrated that immunoreactive $\operatorname{ER} \alpha$ was found throughout the epididymis with the initial segment strongest, similar to the expression profile measured in the 3 -day high phytoestrogen group. This may reflect the formula of the rat chow used in that study.

Disruption of oestrogen action, by the removal of functional $E R \alpha$ in mice (Eddy et al. 1996, Hess et al. 1997a) or the administration of an anti-oestrogen to adult rats (Oliveira et al. 2001) causes reduced fluid absorption in the excurrent duct system, leading to lumen distention and flattening of epithelial cell height. This did not appear to be a factor in this study. No change in tubule or lumen diameter was determined. Furthermore, the ratio of lumen to tubule diameters, an indication of epithelial cell height, was not affected.

During storage in the epididymis, sperm must be protected from damage caused by reactive oxygen species (Aitken \& Vernet 1998). The epididymis provides protection by the secretion of antioxidant enzymes (Zini \& Schlegel 1997) under steroid regulation (Schwaab et al. 1998). As it takes 8-9 days for sperm to transit the epididymis of the rat, the last 5 days being spent in the cauda epididymis (Robb et al. 1978), it is likely then that disruption of caudal sperm is responsible for the decreased fertility seen after 3 days on the high phytoestrogen diet. Sperm in the cauda epididymis are particularly susceptible to oxidative stress (Tramer et al. 1998). This study has shown that sperm lipid peroxidation is significantly increased in epididymal sperm of rats fed the high phytoestrogen diet for 3 days. This coincides with the changes in ER $\alpha$ and AR in the cauda epididymis. Lipid peroxidation has detrimental effects on sperm function, reducing motility and the ability to fuse with an oocyte (Aitken et al. 1993). The reduction of epididymal protective strategies by oestrogenic chemicals has been previously demonstrated. Bisphenol A, a chemical with known oestrogenic activity (Kuiper et al. 1997, Steinmetz et al. 1998), has been shown to reduce antioxidant enzyme activity in the epididymis and to increase lipid peroxidation of epididymal sperm (Chitra et al. 2003). To demonstrate unequivocally that lipid peroxidation of sperm is the cause of reduced litter size, one would need to demonstrate that lipid peroxidation was not induced by a high phytoestrogen diet for those time-points where litter size was unaltered. However, the increase in sperm lipid peroxidation seen after 3 days of exposure coincides with induced changes in $\operatorname{ER} \alpha$ and AR expression in the cauda epididymis. No changes in these steroid hormone receptors occurred after 6 days and hence we predict that sperm lipid peroxidation would also be unaltered.
In conclusion, acute exposure of adult male rats to a diet of high phytoestrogen content transiently reduces their fecundity. This effect coincides with altered expression of epididymal AR and ER $\alpha$, indicating disrupted epididymal function. We propose that the reduction in fecundity results from reduced steroid-regulated antioxidant protection in the epididymis, leading to oxidative damage and loss of sperm function.

\section{Funding}

This work was supported by a University of Otago Research Grant (200100543) and a Community Trust of Otago Annual Grant (224). The authors declare that there is no conflict of interest that would prejudice the impartiality of this scientific work.

\section{References}

Aceitero J, Llanero M, Parrado R, Pena E \& Lopez-Beltran A 1998 Neonatal exposure of male rats to estradiol benzoate causes rete testis dilation and backflow impairment of spermatogenesis. Anatomical Record 252 17-33.

Adachi T, Ono Y, Koh K-B, Takashima K, Tainaka H, Matsuno Y, Nakagawa S, Todaka E, Sakurai K, Fukata H et al. 2004 Long-term alteration of gene expression without morphological change in testis after neonatal exposure to genistein in mice: toxicogenomic analysis using cDNA microarray. Food and Chemical Toxicology $42445-452$.

Adlercreutz H, Markkanen H \& Watanabe S 1993 Plasma concentrations of phyto-estrogens in Japanese men. Lancet 342 1209-1210.

Aitken RJ \& Vernet P 1998 Maturation of redox regulatory mechanisms in the epididymis. Journal of Reproduction and Fertility 53 (Suppl) 109-118.

Aitken RJ, Harkiss D \& Buckingham D 1993 Relationship between iron-catalysed lipid peroxidation potential and human sperm function. Journal of Reproduction and Fertility 98 257-265.

Ashby J, Tinwell H, Lefevre PA, Joiner R \& Haseman J 2003 The effect on sperm production in adult Sprague-Dawley rats exposed by gavage to bisphenol A between postnatal days 91-97. Toxicological Sciences 74 129-138.

Atanassova N, Mckinnell C, Williams K, Turner KJ, Fisher JS, Saunders PTK, Millar MR \& Sharpe RM 2001 Age-, cell- and region-specific immunoexpression of oestrogen receptor $\alpha$ (but not oestrogen receptor $\beta$ ) during postnatal development of the epididymis and vas deferens of the rat and disruption of this pattern by neonatal treatment with diethylstilbestrol. Endocrinology 142 874-886.

Atanassova NN, Walker M, McKinnell C, Fisher JS \& Sharpe RM 2005 Evidence that androgens and oestrogens, as well as follicle-stimulating hormone, can alter Sertoli cell number in the neonatal rat. Journal of Endocrinology 184 107-117.

Chitra KC, Latchoumycandane C \& Mathur PP 2003 Induction of oxidative stress by bisphenol A in the epididymal sperm of rats. Toxicology 185 119-127.

Chu S \& Fuller PJ 1997 Identification of a splice variant of the rat oestrogen receptor $\beta$ gene. Molecular and Cellular Endocrinology 132 195-199.

Cruz-Orive LM 1987 Particle number can be estimated using a disector of unknown thickness: the selector. Journal of Microscopy $145121-142$ 
Eddy EM, Washburn TF, Bunch DO, Goulding EH, Gladen BC, Lubahn DB \& Korach KS 1996 Targeted disruption of the estrogen receptor gene in male mice causes alteration of spermatogenesis and infertility. Endocrinology 137 4796-4805.

Faqi AS, Johnson WD, Morrissey RL \& McCormick DL 2004 Reproductive toxicity assessment of chronic dietary exposure to soy isoflavones in male rats. Reproductive Toxicology 18 605-611.

Fisher JS, Millar MR, Majdic G, Saunders PTK, Fraser HM \& Sharpe RM 1997 Immunolocalisation of oestrogen receptor- $\alpha$ within the testis and excurrent ducts of the rat and marmoset monkey from perinatal life to adulthood. Journal of Endocrinology 153 485-495.

Fisher JS, Turner KJ, Fraser HM, Saunders PTK, Brown D \& Sharpe RM 1998 Immunoexpression of aquaporin-1 in the efferent ducts of the rat and marmoset monkey during development, its modulation by estrogens, and its possible role in fluid resorption. Endocrinology 139 3935-3945.

Fisher JS, Turner KJ, Brown D \& Sharpe RM 1999 Effect of neonatal exposure to estrogenic compounds on development of the excurrent ducts of the rat testis through puberty to adulthood. Environmental Health Perspectives 107 397-405.

Fritz WA, Wang J, Eltoum I-E \& Lamartiniere CA 2002 Dietary genistein down-regulates androgen and estrogen receptor expression in the rat prostate. Molecular and Cellular Endocrinology $18689-99$

Goyal HO, Braden TD, Mansour M, Williams CS, Kamaleldin A \& Srivastava KK 2001 Diethylstilbestrol-treated adult rats with altered epididymal sperm numbers and sperm motility parameters, but without alterations in sperm production and sperm morphology. Biology of Reproduction 64 927-934.

Goyal HO, Robateau A, Braden TD, Williams CS, Srivastava KK \& Ali K 2003 Neonatal estrogen exposure of male rats alters reproductive functions at adulthood. Biology of Reproduction 68 2081-2091.

Hess RA, Bunick D, Lee K, Taylor JA, Korack KS \& Lubahn DB $1997 a$ A role for oestrogens in the male reproductive system. Nature 390 509-512.

Hess RA, Gist DH, Bunick D, Lubahn DB, Farrell A, Bahr J, Cooke PS \& Greene GL $1997 b$ Estrogen receptor $(\alpha$ and $\beta$ ) expression in the excurrent ducts of the adult male rat reproductive tract. Journal of Andrology 18 602-611.

Hess RA, Bunick D, Lubahn DB, Zhou Q \& Bouma J 2000 Morphologic changes in efferent ductules and epididymis in estrogen receptor- $\alpha$ knockout mice. Journal of Andrology 21 $107-121$

Jervis KM \& Robaire B 2001 Dynamic changes in gene expression along the rat epididymis. Biology of Reproduction 65 696-703.

Kuiper GGJM, Enmark E, Pelto-Huikko M, Nilsson S \& Gustafsson J-Å 1996 Cloning of a novel estrogen receptor expressed in rat prostate and ovary. PNAS 93 5925-5930.

Kuiper GGJM, Carlsson B, Grandien K, Enmark E, Häggblad J, Nilsson S \& Gustafsson J-Å 1997 Comparison of the ligand binding specificity and transcript distribution of estrogen receptors $\alpha$ and $\beta$. Endocrinology 138 863-870.

Kuiper GGJM, Lemmen JG, Carlsson B, Corton JC, Safe SH, van der Saag PT, van der Burg B \& Gustafsson J-Å 1998 Interaction of estrogenic chemicals and phytoestrogens with estrogen receptor $\beta$. Endocrinology 139 4252-4263.

Lubahn DB, Moyer JS, Golding TS, Couse JF, Korach KS \& Smithies O 1993 Alteration of reproductive function but not prenatal sexual development after insertional disruption of the mouse estrogen receptor gene. PNAS 90 11162-11166.

Mitchell JH, Cawood E, Kinniburgh D, Provan A, Collins AR \& Irvine DS 2001 Effect of a phytoestrogen food supplement on reproductive health in normal males. Clinical Science 100 613-618.

Nicholson HD, Guldenaar SEF, Boer GJ \& Pickering BT 1991 Testicular oxytocin: effects of intratesticular oxytocin in the rat. Journal of Endocrinology 130 231-238.
Ohkawa H, Ohishi N \& Yagi K 1979 Assay for lipid peroxides in animal tissues by thiobarbituric acid reaction. Analytical Biochemistry 95 351-358.

Oliveira CA, Carnes K, França LR \& Hess RA 2001 Infertility and testicular atrophy in the antiestrogen-treated adult male rat. Biology of Reproduction 65 913-920.

Oliveira CA, Mahecha GAB, Carnes K, Prins GS, Saunders PTK, França LR \& Hess RA 2004 Differential hormonal regulation of estrogen receptors $\mathrm{ER} \alpha$ and $\mathrm{ER} \beta$ and androgen receptor expression in rat efferent ductules. Reproduction 128 73-86.

Rannikko A, Petas A, Rannikko S \& Adlercruetz H 2006. Plasma and phytoestrogen concentrations in prostate cancer patients after oral phytoestrogen supplementation. Prostate 66 82-87.

Robb GW, Amann RP \& Killian GJ 1978 Daily sperm production and epididymal sperm reserves of pubertal and adult rats. Journal of Reproduction and Fertility 54 103-107.

Sar M \& Welsh F 2000 Oestrogen receptor alpha and beta in rat prostate and epididymis. Andrologia 32 295-301.

Schwaab V, Lareyre JJ, Vernet P, Pons E, Faure J, Dufaure JP \& Drevet JR 1998 Characterization, regulation of the expression and putative roles of two glutathione peroxidase proteins found in the mouse epididymis. Journal of Reproduction and Fertility 53 (Suppl) $157-162$.

Serre V \& Robaire B 1998 Segment-specific morphological changes in aging brown Norway rat epididymis. Biology of Reproduction 58 497-513.

Sharpe RM, Rivas A, Walker M, McKinnell C \& Fisher JS 2003 Effect of neonatal treatment of rats with potent or weak (environmental) oestrogens, or with a GnRH antagonist, on Leydig cell development and function through puberty into adulthood. International Journal of Andrology 26 26-36.

Sokal RR \& Rohlf FJ 1981 Biometry, edn 2. New York, NY, USA: Freeman and Co.

Steinmetz R, Mitchner NA, Grant A, Allen DL, Bigsby RM \& Ben-Jonathan N 1998 The xenoestrogen bisphenol A induces growth, differentiation, and c-fos gene expression in the female reproductive tract. Endocrinology 139 2741-2747.

Taylor GT, Weiss J, Frechmann T \& Haller J 1985 Copulation induces an acute increase in epididymal sperm numbers in rats. Journal of Reproduction and Fertility 73 323-327.

Tramer F, Rocco F, Micali F, Sandri G \& Panfili E 1998 Antioxidant systems in rat epididymal spermatozoa. Biology of Reproduction $59753-758$.

Wang J, Eltoun IE, Lamartiniere CA 2002 Dietary genistein suppresses chemically induced prostate cancer in Lobund-Wistar rats. Cancer Letters 186 11-18.

Weber KS, Setchell KDR, Stocco DM \& Lephart ED 2001 Dietary soy-phytoestrogens decrease testosterone levels and prostate weight without altering LH, prostate $5 \alpha$-reductase or steroid acute regulatory peptide levels in adult male Sprague-Dawley rats. Journal of Endocrinology 170 591-599.

Yamashita S 2004 Localization of estrogen and androgen receptors in male reproductive tissues of mice and rats. Anatomical Record 279A 768-778.

Yeung WS, Guldenaar SE, Worley RT, Humphrys J \& Pickering BT 1988 Oxytocin in Leydig cells: an immunocytochemical study of Percoll-purified cells from rat testes. Cell and Tissue Research 253 463-468.

Zini A \& Schlegel PN 1997 Identification and characterization of antioxidant enzyme mRNAs in the rat epididymis. International Journal of Andrology 20 86-91.

Received in final form 13 February 2006

Accepted 13 March 2006

Made available online as an Accepted Preprint

22 March 2006 